\title{
Early Origins of Overeating: Tracking Between Early Food Habits and Later Eating Patterns
}

\author{
Sophie Nicklaus • Eloïse Remy
}

Published online: 7 March 2013

(C) Springer Science+Business Media New York 2013

\begin{abstract}
This review considers papers published in the last decade in relation to tracking between early food habits (here, habits acquired before 10 years) and later eating patterns. This review analyzes first how later eating patterns may be associated with the mode of milk feeding (formula vs. breast feeding; type of formula) and with the way complementary feeding is conducted (timing and type/variety of foods offered). Beyond the first year, this review focuses on the tracking of food preferences, food variety, portion size, dietary intake and eating traits. Most studies revealed moderate but significant associations between mode of milk feeding and complementary feeding practices and later eating patterns. When the baseline period is beyond 1 year, a moderate level of tracking is also observed for most eating behaviors reported (food preferences; food variety; dietary intake; eating traits), revealing a consistency over time in eating behavior; however eating behavior is likely to evolve when children grow older.
\end{abstract}

Keywords Tracking $\cdot$ Eating behavior $\cdot$ Food habits .

Prospective studies · Food preference · Food variety $\cdot$ Energy intake $\cdot$ Dietary intake $\cdot$ Eating in the absence of hunger .

\author{
S. Nicklaus $\cdot$ E. Remy \\ CNRS, UMR6265 Centre des Sciences du Goût et de \\ l'Alimentation, F-21000, Dijon, France \\ S. Nicklaus $\cdot$ E. Remy \\ INRA, UMR1324 Centre des Sciences du Goût et de \\ l'Alimentation, F-21000, Dijon, France \\ S. Nicklaus $\cdot$ E. Remy \\ Université de Bourgogne, UMR Centre des Sciences du Goût et de \\ l'Alimentation, F-21000, Dijon, France \\ S. Nicklaus $(\bowtie)$ \\ UMR CSGA, INRA, 17 rue Sully, \\ 21000, Dijon, France \\ e-mail: sophie.nicklaus@dijon.inra.fr
}

Breastfeeding $\cdot$ Complementary feeding $\cdot$ Pickiness · Fussiness $\cdot$ Infants $\cdot$ Children $\cdot$ Overeating

\section{Introduction}

The importance of early nutritional status on the health of the adult has been recognized more than 20 years ago [1]. Early nutrition is dependent on the early feeding practices adopted by parents and thus on food habits acquired by children. Foods habits formed early are likely to track later in childhood and to form the basis of the eating patterns of the adult. The aim of the present review is to summarize findings from studies published in the last decade concerning associations between early food habits and later eating patterns. This review focuses on the child's food habits, excluding the association between parental diets or feeding practices and children's food habits; and focuses on early habits, here defined as habits observed during the first 10 years of life. The literature search was conducted in the PubMed and WOS databases using combinations of keyword [(energy intake / portion size / caloric compensation / eating in the absence of hunger / food variety / food preference / intake / food habits / eating habit / eating patterns) combined with (child) and (prospective / long-term / cohort / longitudinal / predict / tracking)], and was complemented by a hand search. This review focuses on publications from the last decade, except when key older references were concerned.

The analysis of the tracking of early eating habits may be analyzed in two ways: the tracking per se may be evaluated, i.e., the association between high level of a given eating habit for a given child in childhood and later on in life, in other words the correlations within a group of individuals between early and later eating patterns; and the evolution in the eating habit, i.e., the comparison of the average level of a given habit at 
different time points. This paper mainly focuses on tracking and thus reports primarily studies in which eating habits were measured at several time points in the same children and in which tracking was assessed, but may also refer to articles reporting data from longitudinal studies in which only evolution was evaluated.

\section{Association between Milk Feeding Practices and Later Eating Patterns}

Milk feeding practices are in a vast majority of cases dependent on the mother's choice to breastfeed or not and thus cannot be viewed as a child's food habit; however, the importance of milk feeding mode in the building of eating habits has been increasingly recognized in the last decade and justifies scrutiny.

Feeding mode may be associated with a differential acceptance of food at the beginning of complementary feeding: breastfeeding leads to a higher acceptance of a new food at weaning when acceptance is evaluated during the first days of the weaning period [2]. However, this association is not observed when acceptance is evaluated after 2 weeks of complementary feeding [3] or when acceptance of new foods is averaged over a two-month period (Lange C, Visalli M, Jacob S, et al. Maternal feeding practices during the first year and their impact on infants' acceptance of complementary food, in review). The positive impact of breastfeeding on further food acceptance may be mediated by flavor exposure in the milk context $[3,4]$.

Taste experience in the milk feeding context may modify further food preferences. The longer the breastfeeding duration, the higher the acceptance of a umami-tasting solution at 6 months [5]. Exposure to hydrolyzed-protein formulas is associated to a different taste preference pattern later, up to the age of 5 years $[6,7]$.

Breastfeeding duration is positively associated to food variety later: it is associated to variety of free food choices by 2-to-3-year-old children [8], to healthy eating habits at 2 years [9], to food variety at 2 years [10], to fruit consumption at $6-8$ years [11] and to a healthy eating patterns (consumption of meat, fruits and vegetables) at 2-8 years [12]. Exclusive breastfeeding for at least 3 months is associated with a higher consumption of vegetables at 4 years [13].

Finally, mode of milk feeding may also be associated with growth curves: breastfed babies are less likely to be overweight or obese at 4 years than formula-fed babies [9]. The type of formula may also matter in relation to growth since in an experimental study, weight gain at ages 2.5 to 7.5 months in infants fed an extensively hydrolyzed protein formula was more normative than that of infants fed cow's milk formula [14]. However, a recent epidemiological report did not show a significant impact of type of formula used and growth at 4 months [15].

\section{Association between Complementary Feeding Practices and Later Eating Patterns}

The analysis of the short-term impact of complementary feeding practices on later food acceptance was partly covered in a recent review [16••]. The impact of timing of complementary feeding and of the type or variety of foods offered at complementary feeding on further eating patterns was considered in some studies and will be detailed here. Age at complementary feeding may vary, despite the fact that the current recommendation is either to breastfeed exclusively until 6 months [17] or to start complementary feeding after 17 weeks and not later than 26 weeks [18].

Age at the beginning of complementary feeding may impact further eating patterns. Compared to infant weaned before 3 months, infants weaned between 4 and 10 months are more likely to develop healthy eating habits at 2 years, and less likely to be overweight or obese at 4 years [9]. Longitudinal data from the British ALSPAC cohort (Avon Longitudinal Study of Parents and Children) showed that introduction of solid foods with lumps between 6 and 9 months or before compared with introduction after 10 months is associated with a more varied diet at 15 months [19], and at 7 years [20]. Infants weaned later were more likely to have feeding problems at the age of 7 years [20].

The data from the ALSPAC cohort also revealed that the exposure to fruits and vegetables at 6 months was not associated with fruit and vegetable frequency of consumption respectively at 7 years when preparation of complementary foods was not taken into account [21]. However, considering food preparation revealed that exposure to home-cooked vegetables or fruits and to raw fruits at 6 months was associated with a higher frequency of consumption and a higher variety of fruits and vegetables at 7 years [21]. The impact of the early frequency of vegetable consumption may interact with age: if the introduction to home-cooked vegetables was early (before 3 months), the frequency of consumption at 6 months had no impact on vegetable consumption at 7 years; whereas if the introduction was delayed beyond $\sim 6$ months, the frequency of consumption at 6 months was positively associated to vegetable consumption at 7 years [21].

Food variety at the beginning of complementary feeding was shown to influence positively food acceptance later in the weaning period, as observed with experimental studies [2, 22, 23] or longitudinal observations from the French OPALINE cohort (Lange C, Visalli M, Jacob S, et al., in review). Fruit variety at weaning was shown to be associated to fruit consumption at 6-8 years [11]. Intake by food groups tracked moderately between 9 and 18 months [24].

Early taste preferences may guide early food preferences: this was observed in particular for some sweet, sour and umami foods which level of acceptance at the first presentation at weaning was positively associated with the infant's liking of the sweet, sour and umami taste in solution, respectively [25]. 


\section{Association between Eating Habits in the Second Year on and Later Eating Patterns}

To further evaluate the association between eating habits in the second year on and later eating patterns, we will delineate with more detail early eating habits by assessing tracking of food preferences, food variety, portion size, dietary intake and eating trait. The fact that the food repertoire is being built at this early period, and that most children reach a period of food neophobia around 2 years $[26,27]$, may alter tracking between eating habits at this age and further in childhood.

\section{Tracking of Food Preferences}

Taste preferences may guide food preferences in childhood as happens earlier in life: at 18 months, fruits, a group of sour foods, were all the more consumed than children liked sour taste [28]. Concerning salty taste, children's salt liking at preschool age is related to salty solutions acceptance or intake at 6 months [29].

In an American longitudinal cohort, food preferences at 23 years appeared to be related to food preference at 4 and 8 years, especially when specific food groups were reported as liked [30]. In a French longitudinal cohort, food choices at 23 years were significantly but moderately related to food preference up to the age of 22 years, especially for cheeses and meat products; and for vegetables only in girls [31]. Tracking of liking of meat products was altered at adolescence in girls [31]. Vegetable preference increased with age; animal foods decreased with age only in girls; preference for starchy foods and cheeses slightly decreased between 3 and 22 years [31]. Data from a longitudinal cohort of American girls (NEEDS cohort) showed that likes and dislikes of snack foods tracked between 5 and 11 years; snacks which were not much liked at 5 were more liked at 11 years [32]. In the same cohort, the stability of the preference-intake association for snack foods was evaluated in a longitudinal way and revealed a strong association between preference and intake, which may decline in girls with higher dietary restraint, weight concern and percent body fat [33]. This suggests that when children grow older tracking of food preferences may be altered by their concerns about weight status, and by their attempts to restrict specific foods which may vary within a population.

\section{Tracking of Food Variety}

As mentioned in the section about the tracking of food habits from complementary feeding onward, the introduction of a variety of foods as early as the beginning of complementary feeding promotes the variety of the diet later on.
Longitudinal observation of free food choices at a French kindergarten canteen revealed that the variety of food choices decreased between 2 years and 2.5 years and then remained constant until the age of 3 years, while at the same time energy intake increased [8]. Variety of the free food choices between 2 and 3 years was associated with the variety of foods consumed up to the age of 22 years [34]; this was true for the variety of foods consumed in general and for the variety of vegetables, meat products (only until the age of 16 years) and dairy products, but not for starchy foods, and mixed dishes. In an American cohort, the variety of fruits in school-aged children was predicted by the variety of fruits consumed at 2 years, but this relation was not observed for vegetables [11].

\section{Tracking of Portion Size}

Few authors have looked at the tracking of portion size in children. One study reported changes in portion size (amount of food eaten at a given eating occasion) in children: between 2 and 5 years, the majority of food portions were stable, and portions decreased for raw carrots and chicken; between 6 and 11 years, the majority of food portions were stable, some portions decreased (for pizza, chicken and margarine) and the portion of corn flakes increased [35]. Tracking of individual portion size is not reported in this study.

\section{Tracking of Dietary Intake by Food Group}

Tracking of energy intake and dietary intake by food groups was covered by a recent review [36••], and the following section will mainly focus on recent papers not considered in this recent review [37-42].

Table 1 summarizes the main information gathered from these studies. When tracking in dietary intake by food groups is studied, it is generally significant [40-42]. Dietary intake is likely to evolve when children grow older: the intake of milk as a beverage decreases [37, 39], while the intake of snacks increases [38].

Other studies investigated the tracking of eating patterns between adolescence and adulthood but will not be reported in more detail since they fall beyond the scope of this review, however, tracking during this period of dietary intake [43-47], or dieting and eating disorders $[48,49]$ has been investigated.

\section{Tracking of Eating Traits}

Eating traits include a cluster of behaviors which influence food intake. For example a trait of concern to parents is their child's picky eating, "characterized by the toddler or child 


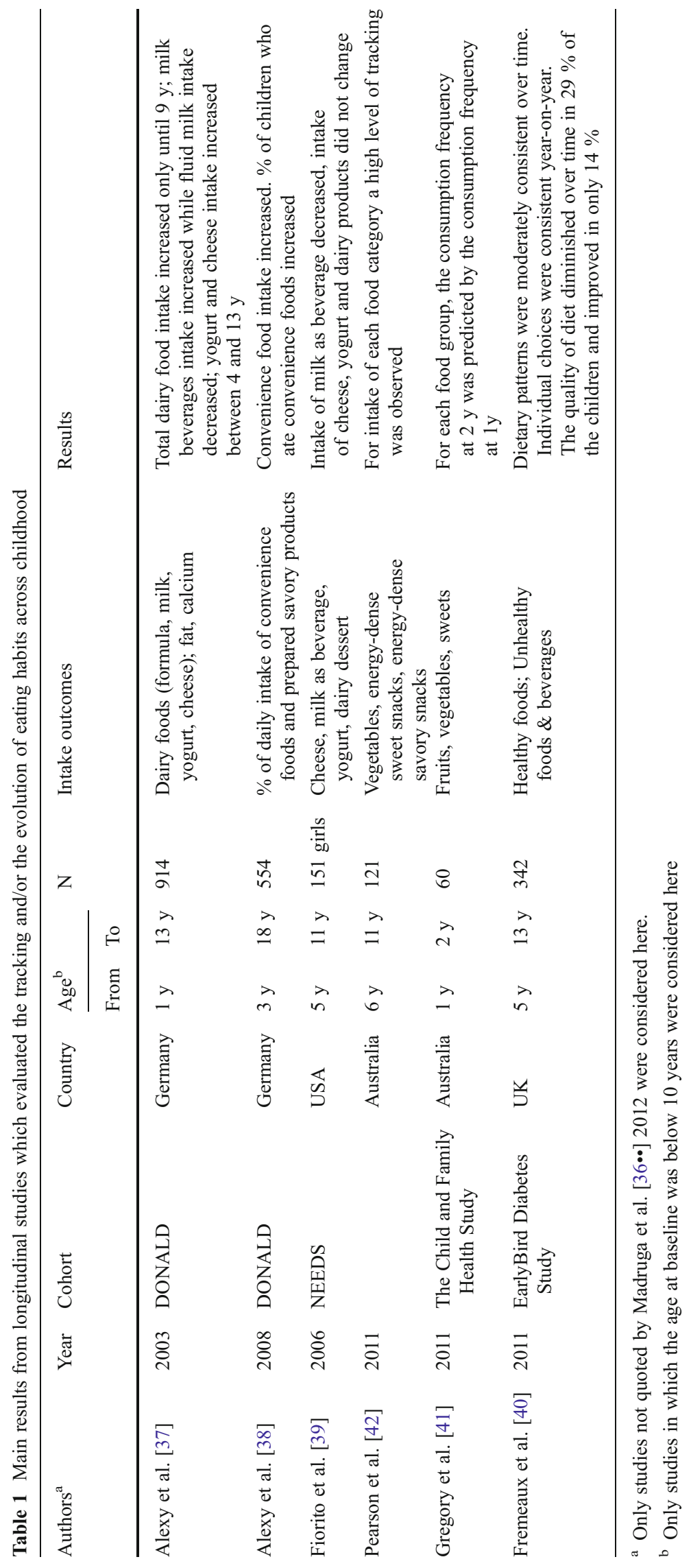


eating a limited amount of food, restricting intake particularly of vegetables, being unwilling to try new foods, and having strong food preferences often leading parents to provide their child a meal different from the rest of the family" [50]. This trait was shown to be fairly stable from 2 to 11 years and may reflect an individual eating style [50]. Level of food fussiness, a trait close to picky eating, defined as "being highly selective about the range of foods that are accepted", was evaluated at the ages of 4 and 11 years and was shown to track significantly in a cohort of English twins [51]. Other eating traits measured by the Child Eating Behaviour Questionnaire were also characterized in this cohort and were shown to track significantly: satiety responsiveness, slowness in eating, food responsiveness, enjoyment of food, emotional overeating; with a lower tracking for emotional undereating [51]. Some traits decreased over time between 2 and 11 years (satiety responsiveness, slowness in eating, food fussiness, and emotional undereating) while other traits increased (food responsiveness, enjoyment of food and emotional overeating) [51].

Another trait which is more related to overeating, eating in the absence of hunger was characterized by a behavioral assessment of children's drive to eat when they have just eaten [52]. The level of eating in the absence of hunger was studied longitudinally from 5 to 9 years in the American NEEDS cohort of girls: it tracked significantly from 5 to 7 years [53] and increased significantly from 5 to 9 years [52]. Another eating trait, inhibitory control, was also characterized in the same cohort [54]. Tracking of this trait was not reported, it was shown that lower level of inhibitory control at the age of 7 years significantly predicted greater weight gain and higher BMI up to the age of 15 years [54].

This analysis reveals that eating traits related to undereating (e.g., picky eating) or overeating (e.g., food responsiveness, eating in the absence of hunger) emerge early in the development and show stability at the individual level, even if they are likely to evolve with age, and thus can be considered as stable personality traits. For further understanding of the association between eating traits and weight gain in childhood, a recent review may be consulted [55•].

\section{Conclusions}

This review highlights the association of breastfeeding with healthy eating patterns further on in childhood. It also reveals that complementary feeding practices (timing, variety of foods offered) are also likely to be associated with healthy eating habits (e.g., fruit and vegetable consumption) later on in development. In the available literature concerning tracking of eating habits after the first year, the majority of studies report moderate tracking from early childhood on, suggesting that certain aspects of eating behavior are fairly stable for a given individual during childhood. The average level of a given eating habit is more likely to evolve with age, especially when the baseline measurement is early in life, because the diet is largely modified qualitatively after the beginning of complementary feeding, when milk intake decreases and other foods are progressively introduced to the child's diet. Altogether, the available results are in broad agreement with the evidence showing strong tracking of body mass index during development in childhood [56•].

Acknowledgments The preparation of this review was made possible thanks to funding from the European Community's Seventh Framework Program (FP7/2007-2013) under the grant agreement n ${ }^{\circ}$ FP7245012-HabEat.

Conflict of Interest Sophie Nicklaus declares that she has no conflict of interest.

Eloïse Rémy declares that she has no conflict of interest.

\section{References}

Papers of particular interest, published recently, have been highlighted as:

- Of importance

-. Of major importance

1. Barker DJ, Osmond C, Golding J, et al. Growth in utero, blood pressure in childhood and adult life, and mortality from cardiovascular disease. BMJ. 1989;298:564-7.

2. Maier AS, Chabanet C, Schaal B, et al. Breastfeeding and experience with variety early in weaning increase infants' acceptance of new foods for up to two months. Clin Nutr. 2008;27:849-57.

3. Hausner $\mathrm{H}$, Nicklaus $\mathrm{S}$, Issanchou $\mathrm{S}$, et al. Breastfeeding facilitates acceptance of a novel dietary flavour compound. Clin Nutr. 2010;29:141-8.

4. Mennella JA, Jagnow CP, Beauchamp GK. Prenatal and postnatal flavor learning by human infants. Pediatrics. 2001;107:e88.

5. Schwartz C, Chabanet C, Laval C, et al. Breastfeeding duration: influence on taste acceptance over the first year of life. Br J Nutr. 2012;4:1-8.

6. Mennella JA, Beauchamp GK. Flavor experiences during formula feeding are related to preferences during childhood. Early Hum Dev. 2002;68:71-82.

7. Liem DG, Mennella JA. Sweet and sour preferences during childhood: role of early experiences. Dev Psychobiol. 2002;41:388-95.

8. Nicklaus S, Chabanet C, Boggio V, Issanchou S. Food choices at lunch during the third year of life: increase in energy intake but decrease in variety. Acta Paediatr. 2005;94:1023-9.

9. Abraham EC, Godwin J, Sherriff A, Armstrong J. Infant feeding in relation to eating patterns in the second year of life and weight status in the fourth year. Public Health Nutr. 2012;15:1705-14.

10. Scott JA, Chih TY, Oddy WH. Food variety at 2 years of age is related to duration of breastfeeding. Nutrients. 2012;4:1464-74.

11. Skinner JD, Carruth BR, Bounds W, et al. Do food-related experiences in the first 2 years of life predict dietary variety in schoolaged children? J Nutr Educ Behav. 2002;34:310-5.

12. Grieger JA, Scott J, Cobiac L. Dietary patterns and breast-feeding in Australian children. Public Health Nutr. 2011;14:1939-47.

13. Burnier D, Dubois L, Girard M. Exclusive breastfeeding duration and later intake of vegetables in preschool children. Eur J Clin Nutr. 2011;65:196-202. 
14. Mennella JA, Ventura AK, Beauchamp GK. Differential Growth Patterns Among Healthy Infants Fed Protein Hydrolysate or CowMilk Formulas. Pediatrics. 2011;127:110-8.

15. Betoko A, Charles MA, Hankard R, et al. Determinants of infant formula use and relation with growth in the first 4 months. Matern Child Nutr. 2012.

16. $\bullet$ Nicklaus S. Children's acceptance of new foods at weaning. Role of practices of weaning and of food sensory properties. Appetite. 2011;57:812-5. Recent review of the role of practices of weaning on children's acceptance of new foods later.

17. WHO Feeding and nutrition of infants and young children. Guidelines for the WHO European region, with emphasis on the former Soviet countries. Geneva, Switzerland: WHO regional publications. European series. 2003;1-288.

18. Agostoni C, Decsi T, Fewtrell M, et al. Complementary feeding: A commentary by the ESPGHAN committee on nutrition. J Pediatr Gastroenterol Nutr. 2008;46:99-110.

19. Northstone K, Emmett P, Nethersole F, et al. The effect of age of introduction to lumpy solids on foods eaten and reported feeding difficulties at 6 and 15 months. J Hum Nutr Diet. 2001;14:43-54.

20. Coulthard H, Harris G, Emmett P. Delayed introduction of lumpy foods to children during the complementary feeding period affects child's food acceptance and feeding at 7 years of age. Matern Child Nutr. 2009;5:75-85.

21. Coulthard H, Harris G, Emmett P. Long-term consequences of early fruit and vegetable feeding practices in the United Kingdom. Public Health Nutr. 2010;13:2044-51.

22. Gerrish CJ, Mennella JA. Flavor variety enhances food acceptance in formula-fed infants. Am J Clin Nutr. 2001;73:1080-5.

23. Mennella JA, Nicklaus S, Jagolino AL, Yourshaw LM. Variety is the spice of life: Strategies for promoting fruit and vegetable acceptance during infancy. Physiol Behav. 2008;94:29-38.

24. Lioret S, McNaughton SA, Spence AC, et al. Tracking of dietary intakes in early childhood: the Melbourne InFANT Program. Eur J Clin Nutr. 2013. doi:10.1038/ejen.2012.218.

25. Schwartz C, Chabanet C, Lange C, et al. The role of taste in food acceptance at the beginning of complementary feeding. Physiol Behav. 2011;104:646-52.

26. Nicklaus S. Development of food variety in children. Appetite. 2009;52:253-5.

27. Dovey TM, Staples PA, Gibson EL, Halford JCG. Food neophobia and 'picky/fussy' eating in children: A review. Appetite. 2008;50:181-93.

28. Blossfeld I, Collins A, Boland S, et al. Relationships between acceptance of sour taste and fruit intakes in 18-month-old infants. Br J Nutr. 2007;98:1084-91.

29. Stein LJ, Cowart BJ, Beauchamp GK. The development of salty taste acceptance is related to dietary experience in human infants: a prospective study. Am J Clin Nutr. 2012;95:123-9.

30. Skinner JD, Carruth BR, Wendy B, Ziegler PJ. Children's food preferences: a longitudinal analysis. J Am Diet Assoc. 2002;102:1638-47.

31. Nicklaus $S$, Boggio $V$, Chabanet $C$, Issanchou $S$. A prospective study of food preferences in childhood. Food Qual Pref. 2004;15:805-18.

32. Rollins BY, Loken E, Birch LL. Stability and change in snack food likes and dislikes from 5 to 11 years. Appetite. 2010;55:371-3.

33. Rollins BY, Loken E, Birch LL. Preferences predict food intake from 5 to 11 years, but not in girls with higher weight concerns, dietary restraint, and \%body fat. Obesity (Silver Spring). 2011;9:2190-7.

34. Nicklaus S, Boggio V, Chabanet $\mathrm{C}$, Issanchou S. A prospective study of food variety seeking in childhood, adolescence and early adult life. Appetite. 2005;44:289-97.

35. Smiciklas-Wright H, Mitchell DC, Mickle SJ, et al. Foods commonly eaten in the United States, 1989-1991 and 1994-1996: are portion sizes changing? J Am Diet Assoc. 2003;103:41-7.

36. • Madruga SW, Araujo CLP, Bertoldi AD, Neutzling MB. Tracking of dietary patterns from childhood to adolescence. Rev Saude
Publica. 2012;46:376-86. Recent review of tracking of dietary patterns from childhood on.

37. Alexy U, Kersting M. Time trends in the consumption of dairy foods in German children and adolescents. Eur J Clin Nutr. 2003;57:1331-7.

38. Alexy U, Sichert-Hellert W, Rode T, Kersting M. Convenience food in the diet of children and adolescents: consumption and composition. Br J Nutr. 2008;99:345-51.

39. Fiorito LM, Mitchell DC, Smiciklas-Wright H, Birch LL. Dairy and dairy-related nutrient intake during middle childhood. J Am Diet Assoc. 2006;106:534-42.

40. Fremeaux AE, Hosking J, Metcalf BS, et al. Consistency of children's dietary choices: annual repeat measures from 5 to 13 years (EarlyBird 49). Br J Nutr. 2011;106:725-31.

41. Gregory JE, Paxton SJ, Brozovic AM. Maternal feeding practices predict fruit and vegetable consumption in young children. Results of a 12-month longitudinal study. Appetite. 2011;57:167-72.

42. Pearson N, Salmon J, Campbell K, et al. Tracking of children's body-mass index, television viewing and dietary intake over fiveyears. Prev Med. 2011;53:268-70.

43. Lake AA, Mathers JC, Rugg-Gunn AJ, Adamson AJ. Longitudinal change in food habits between adolescence (11-12 years) and adulthood (32-33 years): the ASH30 study. J Pub Health. 2006;28:10-6.

44. Lake AA, Adamson AJ, Craigie AM, et al. Tracking of dietary intake and factors associated with dietary change from early adolescence to adulthood: the ASH30 study. Obesity Facts. 2009;2:157-65.

45. Bere E, Brug J, Klepp K-I. Why do boys eat less fruit and vegetables than girls? Public Health Nutr. 2008;11:321-5.

46. Larson NI, Neumark-Sztainer DR, Story MT, et al. Fast food intake: Longitudinal trends during the transition to young adulthood and correlates of intake. J Adol Health. 2008; 43:79-86.

47. Patterson E, Warnberg J, Kearney J, Sjostrom M. The tracking of dietary intakes of children and adolescents in Sweden over six years: the European Youth Heart Study. Int J Behav Nutr Phys Act. 2009;6:91.

48. Field AE, Austin SB, Taylor CB, et al. Relation between dieting and weight change among preadolescents and adolescents. Pediatrics. 2003;112:900-906.

49. Neumark-Sztainer D, Wall M, Larson NI, et al. Dieting and disordered eating behaviors from adolescence to young adulthood: findings from a 10-year longitudinal study. J Am Diet Assoc. 2011;111:1004-1011.

50. Mascola AJ, Bryson SW, Agras WS. Picky eating during childhood: a longitudinal study to age 11 years. Eat Behav. 2010;11:253-257.

51. Ashcroft J, Semmler C, Carnell S, et al. Continuity and stability of eating behaviour traits in children. Eur J Clin Nutr. 2008;62:98590.

52. Birch LL, Fisher JO, Davison KK. Learning to overeat: maternal use of restrictive feeding practices promotes girls' eating in the absence of hunger. Am J Clin Nutr. 2003;78:215-20.

53. Fisher JO, Birch LL. Eating in the absence of hunger and overweight in girls from 5 to $7 \mathrm{y}$ of age. Am $\mathrm{J}$ Clin Nutr. 2002;76:226-31.

54. Anzman SL, Birch LL. Low inhibitory control and restrictive feeding practices predict weight outcomes. J Pediatr. 2009;155:651-6.

55. - French SA, Epstein LH, Jeffery RW, et al. Eating behavior dimensions. Associations with energy intake and body weight. A review. Appetite. 2012;59:541-9. Recent review of the association of eating behaviour dimensions with body weight.

56. - Bayer O, Kruger H, von Kries R, Toschke AM. Factors associated with tracking of BMI: a meta-regression analysis on BMI tracking. Obesity (Silver Spring). 2011;19:1069-76. Recent meta-analysis of the tracking of BMI from early childhood on. 